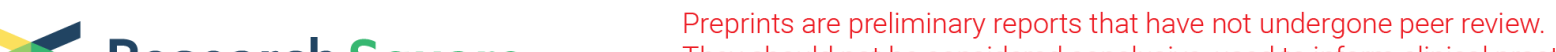 Research Square They should not be considered conclusive, used to inform clinical practice, or referenced by the media as validated information.
}

\section{Effect of Continuous Infusion of Dexmedetomidine on Blood Loss in Orthognathic Surgery: A Retrospective Study}

\section{Chenyu Jin}

Shanghai Ninth People's Hospital

Hong Jiang

Shanghai Ninth People's Hospital

\section{Xiang Lv}

Shanghai Ninth People's Hospital

Yu Sun ( $\nabla$ sunyu_9hospital@163.com )

Shanghai Ninth People's Hospital https://orcid.org/0000-0002-7794-9148

\section{Research}

Keywords: Dexmedetomidine, blood loss, orthognathic surgery

Posted Date: December 23rd, 2020

DOI: https://doi.org/10.21203/rs.3.rs-131518/v1

License: (a) (i) This work is licensed under a Creative Commons Attribution 4.0 International License.

Read Full License

Version of Record: A version of this preprint was published at European Journal of Medical Research on July 20th, 2021. See the published version at https://doi.org/10.1186/s40001-021-00551-5. 


\section{Abstract}

Background: Patients with maxillofacial deformities require orthognathic surgeries to correct occlusion. The surgical procedure may lead to massive bleeding, which is associated with hematoma, respiratory obstruction, and asphyxia. Dexmedetomidine has been used in controlled hypotension, and may decrease blood loss in orthognathic surgery. We conducted a retrospective cohort study to evaluate the effect of dexmedetomidine on blood loss in orthognathic surgeries.

Methods: The primary outcome examined was blood loss, and secondary outcomes were postoperative haemoglobin level, intraoperative heart rate, and blood pressure (T0: preoperative; T1: at incision; T2: 30 minutes after incision; T3: 60 minutes after incision; T4: 120 minutes after incision); dose of fentanyl, remifentanil, urapidil, and esmolol; operation time; incidence of allogeneic blood transfusion; crystalloid fluids volume; and colloidal fluid volume.

Results: A total of 1,247 patients were included in the study, and 557 patient pairs were matched via propensity score matching. There were significant decreases in mean blood loss, heart rate at T1-T4, blood pressure at T1, remifentanil and esmolol dosage, and crystalloid fluid volume in the dexmedetomidine group compared with those in the control group. There was also a significant increase in the postoperative haemoglobin level of the dexmedetomidine group.

Conclusions: Continuous infusion of dexmedetomidine can decrease blood loss in orthognathic surgery.

Trial registration number: ChiCTR1800018794 (retrospectively registered)

Name of registry: Chinese Clinical Trial Registry

Date of registration: 2018/10/09

URL: www.chictr.org.cn/showproj.aspx?proj=30612

\section{Background}

Patients with maxillofacial deformities require orthognathic surgeries (Le Fort I osteotomy and bilateral sagittal split ramus osteotomy) to correct the inconsistent occlusion [1, 2]. The rich blood supply and deep surgical site of the oral and maxillofacial region often lead to increased bleeding and a limited visual field during the osteotomy of the maxilla, thus increasing the risk posed by surgery. Intraoperative haemorrhage is associated with many postoperative complications, such as hematoma, respiratory obstruction, and even asphyxia [3]. Controlled hypotension has been previously used to decrease bleeding in many maxillofacial surgeries [4,5]. Many anaesthetic and vasoactive drugs have been used successfully to achieve controlled hypotension [6]. Dexmedetomidine is a potent, highly selective $\mathrm{a}_{2}$ adrenoceptor agonist that may provide anti-sympathetic analgesia and sedation without respiratory depression [7], and it has been successfully used for controlled hypotension in other surgical procedures [8]. 
The sedative and analgesia-sparing effects of dexmedetomidine are associated with its effects on the central nervous system in the locus coeruleus and spinal cord dorsal horn neurons [9]. Dexmedetomidine is an $\mathrm{a}_{2}$-adrenoreceptor agonist. It primarily inhibits norepinephrine release and causes attenuation of excitation in the central nervous system [10]. Binding of postsynaptic receptors by $a_{2}$-agonists leads to inhibition of sympathetic activity, which decreases the blood pressure (BP) and heart rate (HR), and results in sedation [11].

This retrospective cohort study aimed to determine the efficacy of dexmedetomidine for managing intraoperative blood loss, perioperative hemodynamics, anaesthetic drug requirements, the incidence of blood transfusion, and length of hospital stay in orthognathic surgeries.

\section{Materials And Methods 2.1 Study design}

The study is registered at Chinese Clinical Trial Registry (ChiCTR1800018794). Ethical approval (SH9H2019-T244-2) was obtained from the Shanghai Ninth People's Hospital Research Ethics Committee. We conducted a retrospective cohort study on patients who underwent orthognathic surgeries between March 2017 and August 2018. Institutional review board approval was obtained before the initiation of this study. Patients with a complete medical history and surgical records were included if they were over 18 years old and underwent elective orthognathic surgery. Patients were excluded from the analysis if they had a history of any of the following: allergies to intraoperative-related drugs, heart-related diseases (New York Heart Association class III or higher), severe pulmonary disease (asthma, chronic obstructive pulmonary disease), or severe liver and kidney dysfunction. Each controlled hypotension strategy is different, and there is currently no unified standard strategy for controlled hypotension. Indications for dexmedetomidine include tracheal intubation and sedation during mechanical ventilation for patients undergoing general anaesthesia, and the administration of dexmedetomidine depends on the judgement of senior anesthesiologists. Patients treated with continuous dexmedetomidine were allocated to the dexmedetomidine group, while patients treated without continuous dexmedetomidine were allocated to the control group.

\subsection{Anaesthesia procedures and perioperative medication}

Upon arrival in the operating room, $\mathrm{HR}, \mathrm{BP}$, and oxygen saturation were monitored by electrocardiography, non-invasive BP monitoring, and pulse oximetry, respectively, before an intravenous cannula was inserted. Induction of anaesthesia was similar in every patient, comprising the intravenous administration of $2 \mathrm{mg}$ midazolam, $2-4 \mu \mathrm{g} / \mathrm{kg}$ fentanyl, $1.5-2.5 \mathrm{mg}$ propofol, and $0.15-0.2 \mathrm{mg} / \mathrm{kg}$ cisatracurium. Patients underwent endotracheal intubation, invasive BP monitoring, and deep-vein catheterisation during anaesthesia induction. According to the requirements of the surgeon, most patients underwent acute normovolemic hemodilution (ANH) after anaesthesia and before the beginning of the main steps of surgery [12]. Patients in the dexmedetomidine group were given a $0.5-1-\mu \mathrm{g} / \mathrm{kg}$ loading dose of 
dexmedetomidine, and $200-400 \mathrm{~mL}$ autologous blood was rapidly extracted before incision. Crystalloid liquids were simultaneously infused to patients to supplement the circulating blood volume, dilute the blood, and reduce the loss of visible blood components during surgery. The extracted autologous blood was transfused back to patients before the end of the operation. This has been reported to be an efficacious, safe, and protective method to reduce the concentration of circulating erythrocytes with minimal effects on clotting factors and platelets $[13,14]$.

At the beginning of the operation, controlled hypotension was administered, and vital signs were closely monitored. Each patient received $4-8 \mathrm{mg} / \mathrm{kg} / \mathrm{h}$ propofol and 6-18 $\mu \mathrm{g} / \mathrm{kg} / \mathrm{h}$ remifentanil intravenously, and $2-3 \%$ sevoflurane via inhalation. Patients were given $0.1 \mathrm{mg}$ fentanyl before incision and later again if necessary. Patients in the dexmedetomidine group received continuous dexmedetomidine at $0.2-$ $0.5 \mu \mathrm{g} / \mathrm{kg} / \mathrm{h}$. Narcotic drugs and analgesics, including dexmedetomidine, were initially infused $10 \mathrm{~min}$ before incision. Mean arterial BP was controlled between $50-60 \mathrm{mmHg}$. If mean arterial BP was too high, $5 \mathrm{mg}$ urapidil or $5-10 \mathrm{mg}$ esmolol was used. If mean arterial BP was $<50 \mathrm{mmHg}, 6 \mathrm{mg}$ ephedrine was used. If a patient was bradycardic during the operation, the infusion of dexmedetomidine was stopped and the patient was excluded from the study. Patients were given $0.5 \mathrm{~g}$ tranexamic acid after incision. Allogeneic blood transfusion was performed if necessary, according to the experience of the surgeon and the anesthesiologist. Several clinical measures were used to indicate allogeneic blood transfusion, including haemoglobin $<70 \mathrm{~g} / \mathrm{L}$, haematocrit $<30 \%$, and blood loss $>15 \%$ of estimated blood volume [15]. In addition, the anesthesiologist and surgeon communicated and arrived at a consensus before the allogeneic transfusion was performed. Administration of all narcotic drugs and analgesics, including dexmedetomidine, was discontinued 15 to 30 min before the end of the operation. When the operation was nearing completion, the patients' BP would be increased to the normal level.

\subsection{Data collection}

Study data were obtained from intraoperative records and the electronic medical record. The primary outcome was intraoperative blood loss. The secondary outcomes were postoperative haemoglobin (patients who received allogeneic blood transfusions were excluded); intraoperative HR and BP (both measured at five points: T0, preoperative; T1, at incision; T2, 30 min after incision; T3, 60 min after incision; T4, 120 min after incision); dosage of fentanyl, remifentanil, urapidil, and esmolol; operation time; incidence of allogeneic blood transfusion; crystalloid fluid volume; and colloidal fluid volume.

A standard operating procedure (SOP) was established to train relevant researchers, research assistants, and statistical analysts. The researcher completed the case report form (CRF) according to the SOP. Two researchers independently entered the data, and the research assistant checked and generated the data query forms (DQF). If the research data was lost in the electronic database, the researchers went to the medical history room to retrieve the paper medical history data for verification. Problems in DQFs would be modified and resolved after discussion. Once the modification was complete, data was locked and passed to the statistical analyst.

\subsection{Data analysis}


Propensity score matching (PSM) was introduced to reduce bias due to confounding factors, which might affect surgical decision-making in patients with maxillofacial deformities. Confounding factors included age, height, weight, sex, preoperative haemoglobin, prothrombin time, activated partial thromboplastin time, and ANH. Patients who underwent orthognathic surgeries were matched at a 1:1 ratio with a caliper width equal to 0.01 , resulting in the same number of patients in both groups. The t-test was used for parametric scale variables. Scale variables were tested for normality with the Kolmogorov-Smirnov test. The chi-square exact test was used for nominal variables. Statistical analyses were performed using SPSS version 25 for Windows (IBM, Armonk, NY). Differences between the two groups were expressed as difference in means, standard deviation (SD), mean difference (MD), or odds ratio (OR) with $95 \%$ confidence intervals $(\mathrm{Cl})$. Statistical significance was defined as a $\mathrm{p}$-value $<0.05$.

\section{Results}

Initially, 1,252 patients were identified for analysis in the defined study time period based on the inclusion criteria. After the researchers checked the medical records, five patients were excluded because infusions of dexmedetomidine were discontinued during operations. A total of 1,247 patients were finally included for analysis. All patients were classified as American Society of Anaesthesiologists class I-II. Dexmedetomidine was used continuously in 560 patients, and they were allocated to the dexmedetomidine group. Dexmedetomidine was administered at a maintenance dose of 0.2$0.5 \mu \mathrm{g} / \mathrm{kg} / \mathrm{h}$. Dexmedetomidine was never used in 687 patients, and they were allocated to the control group. PSM was conducted to randomise and control variables, and 557 pairs of patients who underwent orthognathic surgeries were matched. No statistically significant differences were noted at baseline between the PSM-adjusted groups. The study process is shown in Fig. 1. Baseline patient characteristics are shown in 
Table $\mathbb{Q}$

baseline patient characteristics after PSM

\begin{tabular}{|llll|}
\hline Variable & $\begin{array}{l}\text { Dexmedetomidine } \\
\text { group }\end{array}$ & Control group & $\begin{array}{c}\text { Adjusted P } \\
\text { Value }\end{array}$ \\
\hline number & 557 & 557 & $/$ \\
\hline Age (y), mean \pm SD & $23.70 \pm 4.36$ & $23.49 \pm 4.27$ & 0.411 \\
\hline Height (cm), mean \pm SD & $166.63 \pm 8.65$ & $166.40 \pm 8.00$ & 0.754 \\
\hline Weight (kg), mean \pm SD & $59.81 \pm 11.68$ & $58.91 \pm 11.13$ & 0.104 \\
\hline Gender (M/F) & $205 / 352$ & $185 / 372$ & 0.209 \\
\hline $\begin{array}{l}\text { Preoperative hemoglobin (g/L), mean } \\
\pm \text { SD }\end{array}$ & $129.49 \pm 14.87$ & $128.42 \pm$ & 0.272 \\
\hline PLT (×10 $/$ L), mean \pm SD & $240.42 \pm 47.89$ & $239.72 \pm$ & 0.444 \\
\hline PT (s), mean \pm SD & $11.40 \pm 0.92$ & $11.37 \pm 0.81$ & 0.920 \\
\hline APTT (s), mean \pm SD & $28.35 \pm 2.38$ & $28.19 \pm 2.34$ & 0.127 \\
\hline ANH(mL), mean \pm SD & $355.30 \pm 128.61$ & $350.45 \pm$ & 0.459 \\
\hline $\begin{array}{l}\text { PSM: Propensity Score Matching; SD: standard deviation; BMl: body mass index; PLT: platelet; PT: } \\
\text { prothrombin time; APTT: activated partial thromboplastin time; ANH: acute normovolemic } \\
\text { hemodilution }\end{array}$ & & & \\
\hline
\end{tabular}

There was a significant decrease in mean blood loss, HR at T1-T4, BP at T1, dosages of remifentanil and esmolol, and crystalloid fluid volume in the dexmedetomidine group. There was a significant increase in postoperative haemoglobin in the dexmedetomidine group. There was no significant difference in operation time, intraoperative HR at T0, intraoperative BP at T0 or T2-T4, incidence of allogeneic blood transfusion, dose of fentanyl or urapidil, or colloidal fluid volume. The results of the primary and

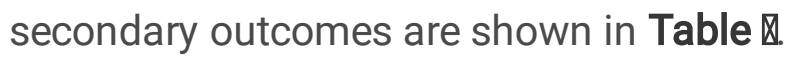


Table $\mathbb{Q}$

primary and secondary outcomes after PSM

\begin{tabular}{|c|c|c|c|c|}
\hline Variable & $\begin{array}{l}\text { Dexmedetomidine } \\
\text { group }\end{array}$ & $\begin{array}{l}\text { Control } \\
\text { group }\end{array}$ & $95 \% \mathrm{Cl}$ & $\begin{array}{l}\text { Adjusted } \\
\text { P Value }\end{array}$ \\
\hline Blood loss $(\mathrm{mL})$, mean \pm SD & $667.95 \pm 272.25$ & $\begin{array}{l}743.54 \\
\pm \\
295.96\end{array}$ & $\begin{array}{l}-108.41 \\
\text { to } \\
-42.76\end{array}$ & $<0.001$ \\
\hline Postoperative hemoglobin $(\mathrm{g} / \mathrm{L})$, mean $\pm \mathrm{SD}$ & $104.49 \pm 14.78$ & $\begin{array}{l}99.21 \pm \\
15.74\end{array}$ & $\begin{array}{l}3.15 \text { to } \\
7.41\end{array}$ & $<0.001$ \\
\hline \multicolumn{5}{|l|}{ Intraoperative HR (bpm), mean \pm SD } \\
\hline T0 & $80.75 \pm 9.32$ & $\begin{array}{l}80.93 \pm \\
11.00\end{array}$ & $\begin{array}{l}-1.47 \\
\text { to } 1.01\end{array}$ & 763 \\
\hline T1 & $70.86 \pm 11.06$ & $\begin{array}{l}78.16 \pm \\
12.93\end{array}$ & $\begin{array}{l}-8.78 \text { to } \\
-5.82\end{array}$ & $<0.001$ \\
\hline T2 & $72.80 \pm 11.26$ & $\begin{array}{l}79.44 \pm \\
11.45\end{array}$ & $\begin{array}{l}-8.00 \text { to } \\
-5.28\end{array}$ & $<0.001$ \\
\hline T3 & $71.82 \pm 10.33$ & $\begin{array}{l}79.45 \pm \\
11.16\end{array}$ & $\begin{array}{l}-8.89 \text { to } \\
-6.36\end{array}$ & $<0.001$ \\
\hline T4 & $69.72 \pm 10.49$ & $\begin{array}{l}78.34 \pm \\
10.56\end{array}$ & $\begin{array}{l}-9.89 \text { to } \\
-7.35\end{array}$ & $<0.001$ \\
\hline \multicolumn{5}{|l|}{ Intraoperative BP $(\mathrm{mmHg})$, mean $\pm \mathrm{SD}$} \\
\hline T0 & $86.48 \pm 8.39$ & $\begin{array}{l}86.76 \pm \\
8.48\end{array}$ & $\begin{array}{l}-1.28 \text { to } \\
0.71\end{array}$ & 0.572 \\
\hline $\mathrm{T} 1$ & $60.26 \pm 9.91$ & $\begin{array}{l}62.93 \pm \\
10.75\end{array}$ & $\begin{array}{l}-3.90 \text { to } \\
-1.43\end{array}$ & $<0.001$ \\
\hline $\mathrm{T} 2$ & $55.89 \pm 7.66$ & $\begin{array}{l}56.83 \pm \\
8.64\end{array}$ & $\begin{array}{l}-1.89 \text { to } \\
0.01\end{array}$ & 0.051 \\
\hline T3 & $54.65 \pm 5.87$ & $\begin{array}{l}55.15 \pm \\
7.17\end{array}$ & $\begin{array}{l}-1.24 \text { to } \\
0.26\end{array}$ & 0.179 \\
\hline T4 & $56.25 \pm 7.93$ & $\begin{array}{l}56.80 \pm \\
8.77\end{array}$ & $\begin{array}{l}-1.54 \text { to } \\
0.43\end{array}$ & 0.271 \\
\hline Operation time $(\mathrm{h})$, mean $\pm \mathrm{SD}$ & $3.56 \pm 1.11$ & $\begin{array}{l}3.68 \pm \\
1.22\end{array}$ & $\begin{array}{l}-0.26 \text { to } \\
0.01\end{array}$ & 0.078 \\
\hline Fentanyl (mg), mean \pm SD & $0.36 \pm 0.07$ & $\begin{array}{l}0.35 \pm \\
0.07\end{array}$ & $\begin{array}{l}-0.01 \text { to } \\
0.01\end{array}$ & 0.582 \\
\hline Remifentanil $(\mathrm{mg})$, mean \pm SD & $1.24 \pm 0.45$ & $\begin{array}{l}1.50 \pm \\
0.59\end{array}$ & $\begin{array}{l}-0.32 \text { to } \\
-0.20\end{array}$ & $<0.001$ \\
\hline $\begin{array}{l}\text { Incidence of allogeneic blood transfusion } \\
\text { (transfused / not transfused) }\end{array}$ & $32 / 525$ & $42 / 515$ & / & 0.229 \\
\hline
\end{tabular}




\begin{tabular}{|c|c|c|c|c|}
\hline Crystalloid fluids $(\mathrm{mL})$, mean \pm SD & $2764.90 \pm 526.26$ & $\begin{array}{l}2839.68 \\
\pm 536.56\end{array}$ & $\begin{array}{l}-135.90 \\
\text { to } \\
-13.65\end{array}$ & 0.017 \\
\hline Colloid fluids $(\mathrm{mL})$, mean \pm SD & $386.89 \pm 348.10$ & $\begin{array}{l}406.64 \\
\pm \\
376.10\end{array}$ & $\begin{array}{l}-63.80 \\
\text { to } 24.30\end{array}$ & 0.379 \\
\hline Urapidil (mg), mean \pm SD & $12.59 \pm 5.86$ & $\begin{array}{l}12.26 \pm \\
5.41\end{array}$ & $\begin{array}{l}-0.35 \text { to } \\
1.02\end{array}$ & 0.34 \\
\hline Esmolol (mg), mean \pm SD & $18.06 \pm 9.94$ & $\begin{array}{l}25.53 \pm \\
10.87\end{array}$ & $\begin{array}{l}-8.71 \text { to } \\
-6.23\end{array}$ & $<0.001$ \\
\hline
\end{tabular}

PSM: Propensity Score Matching; MD: mean difference; OR: odds ratio; Cl: confidence interval; SD: standard deviation; bpm: beat per minute; ICU: Intensive Care Unit

T0: preoperative; T1: at incision; T2: 30 minutes after incision; T3: 60 minutes after incision; T4: 120 minutes after incisi

\section{Discussion}

The results showed a significant decrease in the mean total calculated blood loss in the dexmedetomidine group compared to that in the control group. This may have been due to the hemodynamic effect of dexmedetomidine. Continuous infusion of dexmedetomidine led to decreased HR and BP, which was caused by a negative feedback loop of norepinephrine. Recent studies have also suggested that dexmedetomidine can decrease blood loss throughout several different surgical procedures $[8,16]$. In previous studies, the surgical field of vision, which significantly affects blood loss, was considered to be directly related to decreased $\operatorname{HR}[17,18]$. There is evidence that decreasing MAP below $70 \mathrm{mmHg}$ increases intraoperative bleeding due to local vasodilation [19], but decreased HR is strongly correlated with cardiac output, which is associated with operative field of vision [18]. In contrast to $a_{2}$ agonists, inhalational anaesthetics lead to vasodilatory effects and reflex tachycardia. Furthermore, opioids are less effective than dexmedetomidine in reducing HR. Decreased mean arterial pressure without controlled HR does not lead to improved visibility or lessened bleeding. In addition, the vasoconstrictive effect of intravenous dexmedetomidine has been demonstrated in animal models [20, 21]. Furthermore, studies have provided evidence that intravenous dexmedetomidine has similar vasoconstrictive effects on human arteries and veins [22]. Contraction of the peripheral vessels caused by intravenous dexmedetomidine would further promote surgical site visualisation and reduction of bleeding. Improved surgical field of vision has been mentioned in other studies [23, 24]. This finding is important since it is closely related to blood loss and ease of operation for surgeons. Unfortunately, because this is a retrospective study, the intraoperative visual field could not be assessed using a numerical rating scale or other quantitative methods. Therefore, we could not verify whether the intraoperative field of vision in orthognathic surgery was improved as in other surgeries. Reduced 
bleeding will lead to fewer complications, such as hematoma, respiratory obstruction, and asphyxia, and will further promote the patient's postoperative recovery.

There was a significant increase in postoperative haemoglobin in patients treated with intraoperative dexmedetomidine. Patients who received allogeneic blood transfusions during operations were excluded because the level of postoperative haemoglobin would be affected. Reduced intraoperative blood loss increased levels of postoperative haemoglobin and improved postoperative safety. Postoperative anaemia is associated with dizziness, tinnitus, fatigue, hypoxia, and other side effects [25]. Postoperative acute anaemia is correlated with an increased risk of injury to major organs, such as the brain, heart, and kidney [26], and elevated haemoglobin levels will help avoid these risks.

There was a significant decrease in the intraoperative HR of patients treated with intraoperative dexmedetomidine. The current study also revealed that deliberate hypotension with lower HR could reduce intraoperative blood loss and improve the surgical field $[27,28]$. Dexmedetomidine decreases HR [29], specifically causing a 16-30\% decrease from baseline at plasma drug concentrations $>1-3 \mathrm{ng} / \mathrm{mL}$ $[30,31]$. There was a significant decrease in intraoperative BP at T1 in patients treated with intraoperative dexmedetomidine. The decreased BP may be caused by transient elevated plasma concentration, and it might further contribute to reduction of intraoperative blood loss in the early surgical procedure. There was no significant difference in the average arterial pressure at most time points due to human control. The anesthesiologist maintained the target BP level after the mean BP reached the target point. In addition, the requirement for esmolol was decreased because of the effect of reducing HR.

There was no difference in operation time between considered groups. Although the amount of blood loss was reduced by dexmedetomidine, the operation time was not shortened. Similar studies have also shown that dexmedetomidine improves the quality of the surgical field without significantly affecting operation time [8, 32]. No difference in the requirement of fentanyl was observed between the groups, but the remifentanil requirement in the dexmedetomidine group was significantly decreased. Studies have shown that long-term and high-dose use of opioids may produce some side effects, such as hyperalgesia, nausea and vomiting, and emergence agitation $[33,34]$. The reduced dosage of remifentanil may help alleviate any hyperalgesia and reduce postoperative nausea and vomiting.

There was no significant difference in the incidence of allogeneic blood transfusion between the groups. This might be due to the low transfusion incidence of this surgical procedure. Most patients who undergo orthognathic surgeries do not need blood transfusion, with the exception of those who experience massive bleeding. Studies have also reported that ANH significantly reduces allogeneic blood transfusion $[12,35]$.

There was no significant difference in colloidal fluid volume. The decreased blood loss and HR, and intraoperative fluid management strategy led to significantly decreased crystalloid fluid volume. In addition, the dose of crystalloid fluids seemed to be large for an average 3.5-h duration of surgery. This may have been caused by heavy bleeding and $\mathrm{ANH}$. Patients were required to be transfused with a large amount of crystalloid liquids after a predetermined amount of autologous blood was rapidly withdrawn 
to supplement blood volume and maintain stable vital signs [36]. This protective measure increased crystalloid fluid dosage.

Although the results are promising, there are some limitations to this study. First, the retrospective nature of this study has inherent limitations and potential interference factors regarding data integrity and homogeneity. However, we have strictly followed the criteria for inclusion and exclusion and have used a rigorous statistical approach to avoid bias. Second, this study was a single-centre retrospective study,

which may have led to selection bias. We expanded the sample size to minimise bias. Third, visualisation was pointed out, but it could not be assessed because of the retrospective nature of this study. We plan to conduct further studies to elaborate on this aspect. Fourth, different drugs, including propofol, remifentanil, and sevoflurane, were administered, and this may have affected the accuracy of our conclusions. We used various methods to ensure the reliability of the conclusions, such as expanding the sample size, PSM, and strict data management. Finally, different surgeons use different approaches; thus, the methodology of each operation are different. For example, some surgeons might think that preoperative $\mathrm{ANH}$ is necessary, while others might not.

The study showed dexmedetomidine decreases blood loss in orthognathic surgeries, and we plan to conduct a randomized controlled study in the future.

\section{Conclusion}

Continuous infusion of dexmedetomidine decreases blood loss in orthognathic surgeries.

Dexmedetomidine also increases postoperative haemoglobin and decreases intraoperative HR.

\section{Abbreviations}

HR: heart rate; BP: blood pressure; ANH: acute normovolemic hemodilution; SOP: standard operating procedure; CRF: case report form; DQF: data query form; PSM: propensity score matching; SD: standard deviation; MD: mean difference; OR: odds ratio; Cl: confidence interval

\section{Declarations}

\section{Ethics approval and consent to participate}

The study is registered at Chinese Clinical Trial Registry (ChiCTR1800018794). Ethical approval (SH9H2019-T244-2) was obtained from Shanghai Ninth People's Hospital Research Ethics Committee.

\section{Consent for publication}

The authors declare that they obtain exemption of informed consent from Shanghai Ninth People's Hospital Research Ethics Committee. 


\section{Availability of data and materials}

The datasets used and/or analysed during the current study are available from the corresponding author on reasonable request.

\section{Competing interests}

The authors declare that they have no competing interests.

\section{Funding}

No funding was provided.

\section{Author contributions}

Chenyu Jin: Conceptualisation, Methodology, Software, Data curation, and Writing- Original draft preparation. Yu Sun: Visualisation, Investigation, Data curation. Xiang Lv: Supervision, Investigation, Software, Data curation. Hong Jiang: Supervision, Writing- Reviewing and Editing.

\section{Acknowledgements}

We would like to thank Editage (www.editage.cn) for English language editing.

\section{References}

1. Takatsuji H, Kobayashi T, Kojima T, Hasebe D, Izumi N, Saito I et al: Effects of orthognathic surgery on psychological status of patients with jaw deformities. Int J Oral Maxillofac Surg 2015, 44(9):1125-1130.

2. Niamtu J, 3rd: Oral and Maxillofacial Surgery Clinics of North America. Complications in cosmetic facial surgery. Preface. Oral and maxillofacial surgery clinics of North America 2009, 21(1):ix-x.

3. Jedrzejewski M, Smektala T, Sporniak-Tutak K, Olszewski R: Preoperative, intraoperative, and postoperative complications in orthognathic surgery: a systematic review. Clinical oral investigations 2015, 19(5):969-977.

4. Anderson JA: Deliberate hypotensive anesthesia for orthognathic surgery: controlled pharmacologic manipulation of cardiovascular physiology. The International journal of adult orthodontics and orthognathic surgery 1986, 1(2):133-159.

5. Lin S, McKenna SJ, Yao CF, Chen YR, Chen C: Effects of Hypotensive Anesthesia on Reducing Intraoperative Blood Loss, Duration of Operation, and Quality of Surgical Field During Orthognathic 
Surgery: A Systematic Review and Meta-Analysis of Randomized Controlled Trials. Journal of oral and maxillofacial surgery : official journal of the American Association of Oral and Maxillofacial Surgeons 2017, 75(1):73-86.

6. Choi WS, Samman N: Risks and benefits of deliberate hypotension in anaesthesia: a systematic review. Int J Oral Maxillofac Surg 2008, 37(8):687-703.

7. Chrysostomou C, Schmitt CG: Dexmedetomidine: sedation, analgesia and beyond. Expert opinion on drug metabolism \& toxicology 2008, 4(5):619-627.

8. Snidvongs K, Tingthanathikul W, Aeumjaturapat S, Chusakul S: Dexmedetomidine improves the quality of the operative field for functional endoscopic sinus surgery: systematic review. The Journal of laryngology and otology 2015, 129 Suppl 3:S8-13.

9. Weerink MA, Struys MM, Hannivoort LN, Barends CR, Absalom AR, Colin P: Clinical Pharmacokinetics and Pharmacodynamics of Dexmedetomidine. Clinical pharmacokinetics 2017.

10. Hsu YW, Cortinez LI, Robertson KM, Keifer JC, Sum-Ping ST, Moretti EW et al: Dexmedetomidine pharmacodynamics: part l: crossover comparison of the respiratory effects of dexmedetomidine and remifentanil in healthy volunteers. Anesthesiology 2004, 101(5):1066-1076.

11. Kauppila T, Kemppainen $P$, Tanila H, Pertovaara A: Effect of systemic medetomidine, an alpha 2 adrenoceptor agonist, on experimental pain in humans. Anesthesiology 1991, 74(1):3-8.

12. Zhou J: A review of the application of autologous blood transfusion. Brazilian journal of medical and biological research = Revista brasileira de pesquisas medicas e biologicas 2016, 49(9):e5493.

13. Practice Guidelines for blood component therapy: A report by the American Society of Anesthesiologists Task Force on Blood Component Therapy. Anesthesiology 1996, 84(3):732-747.

14. Ickx BE, Rigolet M, Van Der Linden PJ: Cardiovascular and metabolic response to acute normovolemic anemia. Effects of anesthesia. Anesthesiology 2000, 93(4):1011-1016.

15. Lu VM, Goyal A, Daniels DJ: Tranexamic Acid Decreases Blood Transfusion Burden in Open Craniosynostosis Surgery Without Operative Compromise. The Journal of craniofacial surgery 2019, 30(1):120-126.

16. Kim H, Ha SH, Kim CH, Lee SH, Choi SH: Efficacy of intraoperative dexmedetomidine infusion on visualization of the surgical field in endoscopic sinus surgery. Korean Journal of Anesthesiology 2015, 68(5):449-454.

17. Eberhart LH, Folz BJ, Wulf H, Geldner G: Intravenous anesthesia provides optimal surgical conditions during microscopic and endoscopic sinus surgery. The Laryngoscope 2003, 113(8):1369-1373.

18. Nair S, Collins M, Hung P, Rees G, Close D, Wormald PJ: The effect of beta-blocker premedication on the surgical field during endoscopic sinus surgery. The Laryngoscope 2004, 114(6):1042-1046.

19. Degoute CS, Ray MJ, Manchon M, Dubreuil C, Banssillon V: Remifentanil and controlled hypotension; comparison with nitroprusside or esmolol during tympanoplasty. Canadian journal of anaesthesia = Journal canadien d'anesthesie 2001, 48(1):20-27. 
20. Flacke JW, Flacke WE, Bloor BC, McIntee DF: Hemodynamic effects of dexmedetomidine, an alpha 2adrenergic agonist, in autonomically denervated dogs. Journal of cardiovascular pharmacology 1990, 16(4):616-623.

21. Lawrence CJ, Prinzen FW, de Lange S: Hemodynamic and coronary vascular effects of dexmedetomidine in the anesthetized goat. Acta anaesthesiologica Scandinavica 1997, 41(7):830836.

22. Talke P, Lobo E, Brown R: Systemically administered alpha2-agonist-induced peripheral vasoconstriction in humans. Anesthesiology 2003, 99(1):65-70.

23. Gousheh SMR, Olapour AR, Nesioonpour S, Rashidi M, Pooyan S: The Effect of Intravenous Infusion of Dexmedetomidine to Prevent Bleeding During Functional Endoscopic Sinus Surgery: A Clinical Trial. Anesthesiology and pain medicine 2017, 7(4):e12682.

24. Ayoglu H, Yapakci O, Ugur MB, Uzun L, Altunkaya H, Ozer $Y$ et al: Effectiveness of dexmedetomidine in reducing bleeding during septoplasty and tympanoplasty operations. $J$ Clin Anesth 2008, 20(6):437-441.

25. Willett LR, Carson JL: Management of postoperative complications: anemia. Clinics in geriatric medicine 2014, 30(2):279-284.

26. Choi YJ, Kim SO, Sim JH, Hahm KD: Postoperative Anemia Is Associated with Acute Kidney Injury in Patients Undergoing Total Hip Replacement Arthroplasty: A Retrospective Study. Anesthesia and analgesia 2016, 122(6):1923-1928.

27. Phillips WA, Hensinger RN: Control of blood loss during scoliosis surgery. Clinical orthopaedics and related research 1988(229):88-93.

28. Richa F, Yazigi A, Sleilaty G, Yazbeck P: Comparison between dexmedetomidine and remifentanil for controlled hypotension during tympanoplasty. Eur J Anaesthesiol 2008, 25(5):369-374.

29. Li A, Yuen VM, Goulay-Dufay S, Kwok PC: Pharmacokinetics and pharmacodynamics of dexmedetomidine. Drug development and industrial pharmacy 2016, 42(12):1917-1927.

30. Dyck JB, Maze M, Haack C, Vuorilehto L, Shafer SL: The pharmacokinetics and hemodynamic effects of intravenous and intramuscular dexmedetomidine hydrochloride in adult human volunteers. Anesthesiology 1993, 78(5):813-820.

31. lirola T, Ihmsen H, Laitio R, Kentala E, Aantaa R, Kurvinen JP et al: Population pharmacokinetics of dexmedetomidine during long-term sedation in intensive care patients. British journal of anaesthesia 2012, 108(3):460-468.

32. Escamilla Y, Cardesín A, Samara L, López S, Izquierdo A, Fradera M: Randomized clinical trial to compare the efficacy to improve the quality of surgical field of hypotensive anesthesia with clonidine or dexmedetomidine during functional endoscopic sinus surgery. 2019, 276(11):3095-3104.

33. Glass PS, Hardman D, Kamiyama Y, Quill TJ, Marton G, Donn KH et al: Preliminary pharmacokinetics and pharmacodynamics of an ultra-short-acting opioid: remifentanil (G187084B). Anesthesia and analgesia 1993, 77(5):1031-1040. 
34. Yu EH, Tran DH, Lam SW, Irwin MG: Remifentanil tolerance and hyperalgesia: short-term gain, longterm pain? Anaesthesia 2016, 71(11):1347-1362.

35. Barile L, Fominskiy E, Di Tomasso N, Alpìzar Castro LE, Landoni G, De Luca M et al: Acute Normovolemic Hemodilution Reduces Allogeneic Red Blood Cell Transfusion in Cardiac Surgery: A Systematic Review and Meta-analysis of Randomized Trials. Anesthesia and analgesia 2017, 124(3):743-752.

36. Oppitz PP, Stefani MA: Acute normovolemic hemodilution is safe in neurosurgery. World neurosurgery 2013, 79(5-6):719-724.

\section{Figures}

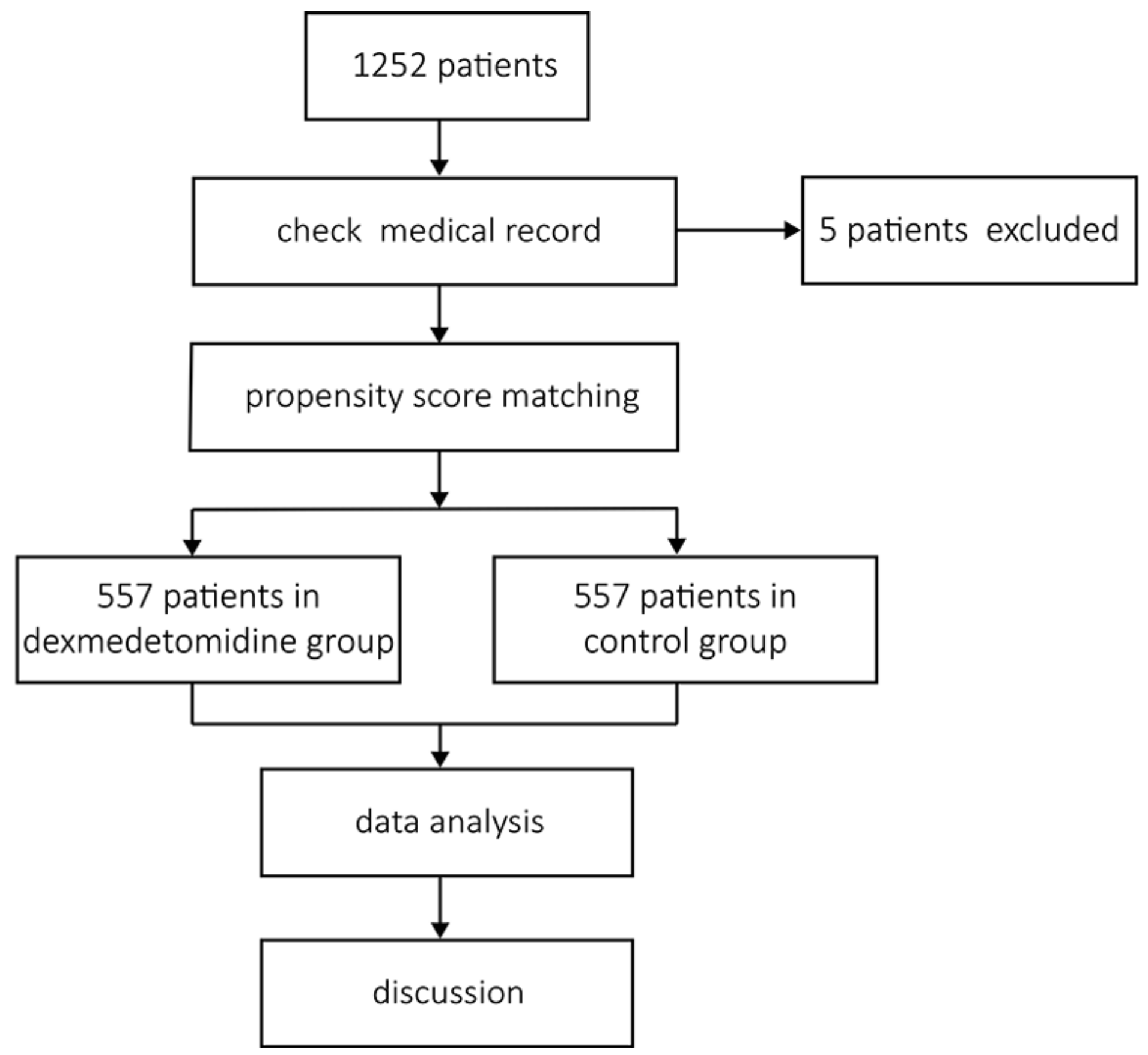


Figure 1

Flow diagram of the study design. 